\title{
O PRINCÍPIO DA CAPACIDADE CONTRIBUTIVA COMO INSTRUMENTO DE POLÍTICAS PÚBLICAS PARA REDUÇÃO DAS DESIGUALDADES SOCIAIS
}

\author{
Lívio Augusto de Carvalho Santos ${ }^{1}$ \\ Jonathan Barros Vita ${ }^{2}$
}

\begin{abstract}
RESUMO: O presente artigo tem como objetivo responder a problemática de como o princípio da capacidade contributiva pode promover a redução das desigualdades sociais? Para tanto, delimita-se o conceito de justiça fiscal e capacidade contributiva, bem como suas relações com a justiça social e o mínimo existencial. Por fim trata da aplicação do referido princípio e a promoção da redução das desigualdades sociais. Conclui-se que o sistema tributário possui instrumentos para aplicação do princípio em comento, concretizando a justiça fiscal, a justiça social e promovendo a redução das desigualdades sociais. A pesquisa é qualitativa, do tipo documental bibliográfica. Utilizou-se do método de abordagem dedutivo e do método de procedimento monográfico, comparativo e funcionalista.
\end{abstract}

Palavras-chaves: Justiça Fiscal; Políticas Públicas; Princípio da capacidade contributiva; Redução das desigualdades sociais.

\section{FAIR TAXATION AND THE REDUCTION OF SOCIAL INEQUALITIES}

\begin{abstract}
Does this article aim to respond to the problem of how the principle of contributory capacity can promote the reduction of social inequalities? To this end, the concept of fiscal justice and contributory capacity is limited, as well as its relations with social justice and the existential minimum. Finally, it deals with the application of that principle and the promotion of reducing social inequalities. It is concluded that the tax system has instruments for the application of the principle in commend, realizing fiscal justice, social justice and promoting the reduction of social inequalities. The research is qualitative, bibliographic documentary type. The method of deductive approach and the method of monographic, comparative and functionalist procedure was used.
\end{abstract}

Keywords: Fair Taxation; Principle of ability to pay; Reduction of social inequalities.

\section{INTRODUÇÃO}

\footnotetext{
${ }^{1}$ Doutorando em Direito da Universidade de Marília - UNIMAR. Mestre em Direito pela Universidade de Santa Cruz do Sul - UNISC. Advogado. Professor da Graduação e da Pós-Graduação em Direito no CESVALE Centro de Ensino Superior do Vale do Parnaíba. Professor do Curso de Bacharelado em Direito da Faculdade CEUPI. Professor do Curso de Bacharelado em Direito da Faculdade do Piauí - FAPI

${ }^{2}$ Doutor e Mestre em Direito pela Pontifícia Universidade Católica de São Paulo - PUCSP. Mestre em Segundo Nível em Direito Tributário de Empresa pela Universitá Commercialle Luigi Bocconi - Milão (Itália). Especialista em Direito Tributário pelo Instituto Brasileiro de Estudos Tributários - IBET. Coordenador e Professor Titular do Programa de Doutorado e Mestrado em Direito da Universidade de Marília - UNIMAR/SP. Advogado. Consultor Jurídico. Contador.
} 
No Brasil persiste uma sociedade dividida em classes marcada pela desigualdade social, havendo concentração da riqueza em pequena parcela da sociedade. Tal desigualdade social é facilmente constatada quando observamos num mesmo espaço geográfico pessoas que tem um alto poder aquisitivo e pessoas que muitas vezes não tem condição de sustento próprio e de sua família.

Segundo o relatório, atualizado em 2018, do Programa das Nações Unidas para o Desenvolvimento - PNUD, a agência líder da rede global de desenvolvimento da ONU e que trabalha principalmente pelo combate à pobreza e pelo Desenvolvimento Humano, o Brasil figura como o terceiro pior país da América Latina em relação ao IDH ajustado à desigualdade, método que relativiza o desenvolvimento humano em função da diferença entre os mais e menos abastados de um país e como nono pior país do mundo em relação Coeficiente de Gini, instrumento que mede o grau de concentração de renda em determinado grupo e aponta a diferença entre os rendimentos dos mais pobres e dos mais ricos.

A Constituição Federal de 1988, em seus arts. $3^{\circ}$ e 170, inciso VII evidenciam o dever do Estado promover a redução das desigualdades sociais, para tanto faz-se necessário a implementação de políticas públicas com o objetivo de dar igualdade de condições e oportunidades.

Neste passo, vale destacar que os tributos são a principal fonte de receita do Estado e são imprescindíveis para a implementação de políticas publicas com a finalidade de concretização dos direitos fundamentais, redução das desigualdades sociais e do desenvolvimento sustentável.

Entretanto, caso a tributação não atenda o critério de justiça fiscal, pode acentuar as desigualdades sociais. Em outras palavras, caso seja tributado mais quem tem uma capacidade menor e tributado menos quem detém uma maior capacidade acarretará num aumento da desigualdade social. Neste contexto, surge a problemática: Como o princípio da capacidade contributiva pode promover a redução das desigualdades sociais?

Portanto, o objetivo do presente artigo é analisar o sistema tributário tomando como critério a justiça fiscal, e o como pode ser alcançado esta justiça fiscal de forma a promover a redução das desigualdades sociais.

Para o desenvolvimento da presente pesquisa, divide-se o trabalho em quatro pontos basilares quais sejam: a densificação da justiça fiscal; o princípio da capacidade contributiva 
como corolário da justiça fiscal; o princípio da capacidade contributiva, o mínimo existencial e a dignidade humana; e o princípio da capacidade contributiva como instrumento de políticas públicas para a redução das desigualdades sociais.

No primeiro tópico, da densificação da justiça fiscal, pretende-se compreender e delimitar o conceito de justiça fiscal, bem como verificar a relação existente entre a justiça fiscal e a justiça social. No segundo tópico, o princípio da capacidade contributiva como corolário da justiça fiscal, pretende-se delimitar o conceito de capacidade contributiva e demonstrar que só é possível alcançar a justiça fiscal com a aplicação do princípio da capacidade contributiva. No terceiro tópico, o princípio da capacidade contributiva, o mínimo existencial e a dignidade humana, pretende-se demonstrar que a parcela destinada à garantia do mínimo existencial e da dignidade humana não podem ser computadas na aferição da capacidade contributiva, logo não podem ser tributadas. Por fim, no quarto tópico pretende-se apontar quais são as ferramentas implementadas pelo Estado com o fito de aplicar o princípio da capacidade contributiva de forma a promover a redução das desigualdades sociais.

Para a elaboração do presente artigo, a pesquisa desenvolvida foi qualitativa do tipo documental bibliográfica, o método de abordagem escolhido foi o dedutivo e como método de procedimento será adotado o método monográfico, comparativo e funcionalista.

\section{DENSIFICAÇÃO DA JUSTIÇA FISCAL}

Porto (2016) afirma que todos os ramos do direto almejam promover o valor da justiça, não sendo diferente o direito tributário, que também buscaria promover o valor da justiça. Aliás, quando o direito tributário regula a atividade tributária de forma a o valor da justiça ele estaria promovendo a justiça fisscal.

Após apresentar a relação entre justiça e direito, Pezzi (2011) explica que a justiça não é uniforme para todo o direito existindo critérios diferentes a depender do ramo do direito, ou seja, em cada ramo do direito foram eleitos critérios distintos para a realização da justiça. No caso particular do direito tributário estes critérios estão vinculados aos princípios, principalmente ao da igualdade e da capacidade contributiva.

\section{Revista de Direito Sociais e Políticas Públicas | e-ISSN: 2525-9881 | Belém | v. 5 | n. 2 |}


A partir disto, podemos concluir que a justiça fiscal é uma espécie autônoma de justiça, dotada de critérios próprios. Neste sentido, Menescal leciona que muito embora seja autônoma a justiça fiscal é a realização da justiça social na seara tributária, senão vejamos:

\begin{abstract}
A consagração da Justiça Fiscal como uma espécie autônoma, tomando-a em sentido estrito, se justifica pela ênfase que se pretende dar aos aspectos ligados ao relacionamento entre indivíduo e Estado arrecadador, e vice-versa. Contudo, há que se considerar que, ainda que se reconheça que certas normas ou certos princípios de justiça fiscal dizem respeito especialmente às relações bilaterais entre o indivíduo e o Estado, toda forma de justiça é, precipuamente, justiça social, na medida em que se aplica à vida em sociedade. (MENESCAL, 2007, p. 38)
\end{abstract}

Na oportunidade, Pezzi (2011) delineia os contornos de justiça social a partir da superação das injustiças na repartição da renda, de forma a disseminar o bem-estar entre a sociedade. Assim, a justiça tributária está intimamente ligada com a justiça social, considerando que com a concretização da justiça fiscal permitiria a concretização da justiça social, pois com a justiça fiscal o ônus tributário é distribuído adequadamente entre os indivíduos da sociedade, acarretando na redistribuição da renda e consequentemente a redução das desigualdades sociais.

Neste sentido, a justiça fiscal e a justiça social pertenceriam à classe lógica de justiça distributiva, que nas palavras de Plauto Faraco "diz respeito à justiça ou injustiça das próprias leis que consagram certas formas de distribuição das rendas, das honras, das posições e de outros bens entre os membros de uma comunidade" (AZEVEDO, 1998, p. 7).

Convergindo com tal pensamento, argumenta Mello (2013, p. 41), citando José Luis Saldanha Sanches, que justiça fiscal é sinônima de justiça tributária e de justiça distributiva:

O conceito de justiça fiscal pode ter diversos significados: o primeiro é o da justiça fiscal no sentido de justiça tributária, que se limita a proceder a uma avaliação quantitativa do modo como são distribuídos os encargos tributários entre os cidadãos e as empresas, ou melhor, entre várias categorias de contribuintes. Perante uma dada carga fiscal, trata-se de saber como é que ela é partida entre os contribuintes com maiores e menores rendimentos. (MELLO, 2013, p. 41)

Torres (S.d.) afirma que a distribuição de rendas e a garantia do mínimo existencial são meios de realização da justiça social. Logo, diante da relação existente entre a justiça social e a justiça fiscal, podemos concluir que a garantia do mínimo existencial também deve ser considerada na concretização da justiça fiscal. 
Corroborando com a ideia de haver uma relação entre a garantia do mínimo existencial e a concretização da justiça fiscal, Peres utilizando dos ensinamentos de Torres leciona:

\footnotetext{
Para tratar da questão da justiça fiscal, além do exame dos elementos apontados, é importante observar a questão do mínimo existencial, incluída na problemática da liberdade. Para uma existência humana digna, o cidadão tem direito a satisfazer suas necessidades mínimas. Esse direito está ligado às condições iniciais de liberdade tema dos direitos fundamentais ou direitos humanos, e está em íntimo contato com a justiça fiscal. (PERES, 2013, p. 66)
}

Defende Conti (1997) que a justiça fiscal tem como principal fundamento a equidade, afirmando que "a justiça fiscal passa a ser aquela fundada na equidade; atingir-se-ia a justiça fiscal por meio da distribuição equitativa do ônus tributário entre os contribuintes" (CONTI, 1997, p.12).

Acrescenta, ainda o autor, que para alcançar um sistema tributário ideal pautado na justiça fiscal é imperioso a aplicação dos princípios do benefício e da capacidade contributiva. Segundo o primeiro "a tributação realizar-se-á de modo que cada contribuinte participe na arrecadação dos tributos na medida dos benefícios que tenha obtido em função dos gastos realizados com os recursos do Estado" (CONTI, 1997, p. 14), já o princípio da capacidade contributiva determina que "os contribuintes devem colaborar para o financiamento dos gastos do Estado na proporção de sua capacidade de contribuição para estes gastos" (CONTI, 1997, p. 14).

Portanto, tanto a justiça fiscal quanto a justiça social buscam uma igualdade formal entre indivíduos de uma sociedade e para tanto se faz necessário a redistribuição de renda. A partir desta ótica, a justiça fiscal e a justiça social teriam como fundamentos a equidade e a redistribuição de renda.

De outro lado, Torres (S.d., p. 31-32) evidencia que numa sociedade complexa a distribuição de renda espontânea é impossível, enfrentando dificuldades o modelo de justiça social e surgindo um novo modelo de justiça a ser perseguido, a justiça política que é um modelo pelo qual o Estado tem um papel preponderante, atuando direta ou indiretamente, para a promoção do desenvolvimento, para tanto o próprio Estado seria responsável por promover a redistribuição de rendas. 
Voltando a obra de Pezzi, a autora afirma que a justiça fiscal pode ser entendida nos sentidos sintático, semântico e pragmático:

\begin{abstract}
O primeiro, reside em sua afirmação como critério seletor de sentido na composição da estrutura semântica das normas jurídicas. Assim, quando na presença de duas ou mais proposições ou sentidos possíveis na composição da norma, a justiça fiscal atua como critério de seleção (justificação) da norma mais adequada ao caso e ao sistema (coerência). De acordo com o sentido semântico, a noção mínima de justiça é extraída das noções de igualdade (capacidade contributiva) e de liberdade (limitações ao poder de tributar). Já no sentido pragmático, a justiça fiscal traduz uma relação de adequação entre a norma e seu usuário, por meio da relação intersistêmica entre política, economia e direito. (PEZZI, 2011, p.65)
\end{abstract}

Além disso, a justiça fiscal seria tanto um princípio estruturante do direito tributário, de onde emanam os princípios da igualdade, da capacidade contributiva, da progressividade, da seletividade e do não confisco, bem como, critério para a interpretação da norma no momento de sua aplicação do caso concreto.

Aliás, segundo Giotti (2014) a justiça fiscal deve ser verificada na elaboração das leis, na interpretação durante a aplicação da lei e após a aplicação da lei com a concretização do direito no caso concreto avaliando se a carga tributária é sustentável segundo os critérios da intensidade da carga tributária para os contribuintes e quanto as reais necessidades das receitas públicas.

A partir disto, podemos concluir que o sistema tributário deve nortear-se pela justiça fiscal de modo a balancear os deveres e direitos dos indivíduos, ou seja, de modo que o dever de recolher os tributos seja distribuído de forma equânime entre os indivíduos respeitado o direito à propriedade, a igualdade e a capacidade contributiva de cada um.

Convém destacar que a justiça fiscal além de servir como parâmetro para repensar a ordem tributária para que a tributação seja distribuída de forma adequada entre os indivíduos da sociedade, respeitando a capacidade contributiva individual, o que permitiria a redistribuição de rendas, é importante instrumento de cidadania, considerando que permite que cada indivíduo contribua, dentro de suas possibilidades, para suprir os gastos do Estado em suas atividades e consequentemente na distribuição do bem comum.

Em outras palavras, com a distribuição adequada do ônus tributário todos conseguiriam cumprir com o dever fundamental de recolher tributo, que é a principal fonte de receita do Estado e permite que o mesmo concretize os direitos dos indivíduos, possibilitando

\author{
Revista de Direito Sociais e Políticas Públicas | e-ISSN: 2525-9881 | Belém | v. 5 | n. 2 | \\ p. 103 - 120 | Jul/Dez. 2019.


que o indivíduo tenha um papel crucial para a construção do bem comum, ou seja, por cumprir com um dever cívico e a partir daí usufruiria de direitos é considerado autêntico cidadão. Por esse ângulo, considerando o dever de pagar tributo como requisito para o exercício da cidadania, a justiça fiscal é imprescindível para o exercício da cidadania.

Como se observou existem várias definições para justiça e diferentes compreensões sobre a justiça fiscal, assim, com o fito de delimitar os conceitos apresentados passaremos a analisar, a relação existente entre a justiça fiscal e o princípio da capacidade contributiva.

\section{O PRINCIPIO DA CAPACIDADE CONTRIBUTIVA COMO COROLÁRIO DA JUSTIÇA FISCAL}

Conforme visto anteriormente, o conceito de justiça fiscal está associado à distribuição adequada do ônus da carga tributária respeitado a capacidade de cada um em suportá-la, bem como que existem vários dispositivos constitucionais que almejam alcança-la. Dentre elas se destaca o que positiva o princípio da capacidade contributiva. Nas palavras de Fernando Aurélio Zilveti “a melhor expressão de justiça fiscal é a capacidade contributiva” (ZELVETI, 2004, p. 124).

Aproveitando as lições de Conti (1997), já expostas anteriormente, temos que para haver um sistema tributário ideal é necessário que o mesmo esteja consoante o ideário da justiça fiscal, o que só poderá ser alcançado com a aplicação de dois princípios, o princípio do benefício e o princípio da capacidade contributiva. Com a aplicação destes dois princípios teríamos que o contribuinte arcaria com o encargo tributário na mediada da sua capacidade de contribuição e na medida em que se usufruísse dos benefícios custeados com recursos públicos. Portanto, os dois princípios são indissociáveis tanto entre si como na relação de ambos com a realização da justiça fiscal.

Segundo Baptista (2007, p. 130) “o princípio da capacidade contributiva em sua essência é um dos vetores da Justiça Distributiva na medida em que visa a distribuir os encargos tributários a cada um segundo a sua capacidade econômica de contribuir".

No mesmo sentido, Iatarola (2005) citando Tipke, ressalta que a justiça no ramo do direito tributário é alcançada pela isonomia, que por sua vez é guiada pelo princípio da 
capacidade contributiva. Sendo este o princípio com critérios mais justo para a aplicação do princípio da igualdade.

Acrescenta, ainda, que o princípio da capacidade contributiva é princípio inerente à justiça fiscal uma vez eu preconiza a tese igualitária, inclusive é o principal princípio de justiça fiscal considerando que na sua observância traz como reflexo a observância de direitos humanos fundamentais da limitação do poder de tributar.

Azevedo (2013) doutrina que o princípio da capacidade contributiva deve ser respeitado desde a elaboração da norma que vier a instituir o tributo, momento em que deverão ser analisadas as desigualdades naturais existentes para impor alguma espécie de discriminação na graduação do tributo, somente sendo justa a atividade tributária do Estado se for adequada à capacidade econômica da pessoa que deva suportar o ônus tributário.

Portanto, conforme a autora o princípio da capacidade contributiva é o instrumento legitimador da discriminação tributária, devendo a estrutura tributária almejá-la com o fito de distribuir adequadamente o ônus tributário entre os indivíduos. Em outras palavras, no momento de legislar par instituir ou majorar um tributo, graduando segundo a capacidade econômica, deve ser adotado um critério de diferenciação. Entretanto, Azevedo (2013) afirma que só haverá justiça fiscal ao escolher o critério de diferenciação deverá se o tratamento diferenciado estiver em conformidades com as diretrizes da Constituição Federal.

Desta forma, evidencia-se que a capacidade contributiva é a medida para a justiça fiscal. Por oportuno, destacamos que segundo Porto (2016, p. 97), citando Tipke, "a avaliação da capacidade contributiva, como medida da tributação, impõe a preservação de um mínimo existencial, partindo-se da premissa de que assegurar a existência digna é compromisso estatal".

Não podemos nos olvidar da proteção à propriedade, que proíbe a tributação excessiva ao ponto de configurar o confisco, devendo também ser considerada a vedação do confisco na graduação do tributo, ou seja, o confisco assim como o mínimo existencial é um parâmetro para a capacidade contributiva. Porto corrobora com o entendimento de que o não confisco está relacionado com a capacidade contributiva.

"Por outro lado, mesmo que observada a proteção do mínimo vital, não se pode admitir que a tributação seja graduada num patamar que imponha restrição ao direito de propriedade, livre iniciativa e até mesmo à liberdade. Nesse sentido, além de um 
limite mínimo, a tributação possui um limite máximo, calcada na ideia de vedação de confisco.” (PORTO, 2016, p. 97)

Trilhando essa faixa, para que a tributação seja considerada justa, dentro das diretrizes da capacidade contributiva, é necessário que a capacidade contributiva não ultrapasse os limites do mínimo existencial e do não confisco.

Por fim, Ricardo Lobo Torres, citado por Gregório (2011, p. 61), “a capacidade contributiva é o princípio mais importante de justiça fiscal, vez que determina a exata contribuição de cada um, proporcionalmente às suas rendas e haveres, independente de sua eventual disponibilidade financeira".

Por outro lado, mesmo reconhecendo a importância do princípio da capacidade contributiva Baptista faz uma crítica à eficácia do princípio alegando que "o sistema tributário brasileiro assenta-se na regressividade, ou seja, aqueles que têm menor capacidade contributiva é que arcam com a maior carga tributária”. (BAPTISTA, 2007, p. 129). Afirma ainda que a eficácia depende do grau de desenvolvimento do povo, trazendo a lição de Hugo de Brito Machado:

A eficácia do princípio da capacidade contributiva, como eficácia de qualquer princípio jurídico, depende do grau de desenvolvimento cultural do povo, que define o grau de disposição das pessoas para defenderem os seus direitos. (BAPTISTA, 2007, p. 130)

Outra crítica de Baptista (2007) é quanto à avaliação da capacidade econômica de contribuir na distribuição dos encargos tributários a cada, não devendo essa avaliação se resumir apenas nos bens patrimoniais do indivíduo, mas também dever considera suas condições pessoais, tais como: "estado civil, saúde, os encargos de família, inclusive a origem das rendas para efeitos de imposições diferenciadas, conforme resulte apenas do trabalho, do emprego de capitais ou de combinação de ambos" (BAPTISTA, 2007, p. 130).

Vale destacar, que mesmo apontando críticas à eficácia e à avaliação da capacidade contributiva Baptista não refuta a ideia de que o princípio da capacidade contributiva é instrumento indispensável para a concretização da justiça fiscal, ao contrário, vai além, afirmando que além de justiça fiscal é possível alcançar a justiça social através do princípio da capacidade contributiva. 
Segundo Baptista (2007, p. 130) "tributando cada um na medida de suas possibilidades o princípio respeita a igualdade tão sonhada e perseguida. $O$ valor arrecadado justamente retorna à sociedade sob a forma de investimentos para aqueles que são mais necessitados". Destacando os investimentos na educação, cultura e informação.

Vale destacar, que tais investimentos são capazes de melhorar a vida das pessoas possibilitando igualdade de condições. Para tanto, além da arrecadação adequada respeitando a capacidade contributiva é necessário a alocação correta dos recursos arrecadados, promovendo a inclusão social.

Nessa mesma linha, Baptista dispõe:

\begin{abstract}
Com uma arrecadação na medida ideal e uma política sincera, esse valor poderia voltar a sociedade sob a forma de investimento na educação, cultura e informação das pessoas e melhora da vida delas redistribuindo e alocando devidamente os bens disponíveis na sociedade.

A alocação correta dos bens de produção e de consumo daria aos indivíduos componentes de nossa sociedade subsídios necessários para que haja uma igualdade de condições materiais (bens de produção de consumo) e imateriais (acesso a cultura, educação e lazer). (BAPTISTA, 2007, p. 131)
\end{abstract}

Por fim, acerca da distribuição dos bens na sociedade, Iatarola anuncia que esta distribuição dos bens na sociedade é denominada de princípio da diferença, tendo três pressupostos. O primeiro pressuposto é a distribuição no âmbito dos bens de forma a trazer um benefício maior para os mais desfavorecidos. O segundo pressuposto é a possibilidade de todos os indivíduos ocuparem posições e funções na sociedade. O terceiro pressuposto é que os indivíduos tenham igualdade de oportunidades com condições mínimas de existência.

Superada a questão da relação entre a justiça fiscal e a capacidade contributiva e depois de concluído que o princípio da capacidade contributiva é um princípio que concretiza a justiça fiscal, analisar-se-á a relação entre o principio da capacidade contributiva com o mínimo existencial e a capacidade contributiva.

\title{
4. A CAPACIDADE CONTRIBUTIVA, O MÍNIMO EXISTENCIAL E A DIGNIDADE HUMANA
}


Conforme explanado anteriormente, o princípio da capacidade contributiva é um instrumento de justiça fiscal, considerando que segundo o mesmo deve ser onerado apenas quem tem capacidade para cumprir a referida exação.

Lembramos que o princípio da capacidade contributiva tem um sentido objetivo e um sentido subjetivo, sendo que no sentido objetivo é uma obrigação a ser cumprida pelo legislador e no sentido subjetivo a capacidade contributiva deve ser analisada no caso concreto, na real aptidão de uma pessoa levando em consideração seus encargos com a sua subsistência e da sua família.

Assim, extrai-se da capacidade econômica do contribuinte o que o onera para a manutenção do mínimo existencial e a dignidade humana. Neste sentido, Regina Costa (2012, p. 71) aduz que "pensamos seja imperioso remarcar que tal noção implica, também, sejam dedutíveis as despesas necessárias à manutenção do contribuinte, seja pessoa física ou jurídica". Complementa ainda a autora dizendo que "isto porque a capacidade contributiva só pode reportar-se existente quando se aferir alguma riqueza acima do "mínimo vital". Este deve ser, pois, intocável (COSTA, 2012, p. 71)".

Então, podemos observar que existe uma relação entre a capacidade contributiva, o mínimo existencial e a dignidade humana.

Este também é o pensamento de Edilson Pereira Nobre Junior ao lecionar,

Outro princípio a que não é alheia a capacidade contributiva é o da dignidade da
pessoa humana. Recolhendo sua inspiração na Declaração Universal dos Direitos
Humanos, aprovada pela Assembleia Geral das Nações Unidas de 10 de dezembro
de 1948 , como repúdio à barbárie nazi-fascista, vem, na atualidade, pautando a
tendência dos ordenamentos constitucionais contemporâneos, através do
reconhecimento do ser humano como o centro e o fim do Direito. Foi, entre nós,
perfilha, à guisa de valor básico do Estado Democrático de Direito (art. $1^{\circ}$, III, CF)
(NOBRE JÚNIOR, 2001, p. 39)

Desse modo, não podemos assentir com a tributação incidente sobre a parcela da riqueza destinada à garantia do mínimo existencial e da dignidade da pessoa humana. Não é outro o pensamento anotado por Carrazza, quando afirma que,

Por outro Lado, os recursos econômicos indispensáveis à satisfação das necessidades básica das pessoas (mínimo vital), garantidas pela Constituição, especialmente em seus art. $6^{\circ}$ e $7^{\circ}$ (alimentação, vestuário, lazer, cultura, saúde, educação, previdência social, transporte etc.), não podem ser alcançados pelos impostos. Tais recursos devem ser salvaguardados pela cuidadosa criação de 
situações de não incidência ou mediante oportunas deduções, legislativamente autorizadas. (CARRAZZA, 2013, p. 116-117)

No mesmo sentido, KLAUS TIPKE e DOUGLAS YAMASHITA ressaltam que:

O princípio da capacidade contributiva protege o mínimo existencial. Enquanto a renda não ultrapassar o mínimo existencial não há capacidade contributiva. $\mathrm{O}$ mesmo resulta da dignidade humana e do princípio do Estado Social. O princípio da capacidade contributiva antes a ambos os princípios.

Não restando dúvidas de que o mínimo existencial e a dignidade humana devem ser levados em consideração na análise da capacidade contributiva. Ao constatar que o mínimo vital e a dignidade humana devem ser protegidos através do princípio da capacidade contributiva, deve-se analisar como o princípio da capacidade contributiva pode ser utilizado como política pública para a redução das desigualdades sociais.

\section{O PRINCIPIO DA CAPACIDADE COMO INSTRUMENTO DE POLÍTICAS PÚBLCIAS PARA A REDUÇÃO DAS DESIGULADADES SOCIAIS}

Logo no início da Constituição, em seu art. $3^{\circ}$, é insculpido o dever de o Estado "erradicar a pobreza e a marginalização e reduzir as desigualdades sociais e regionais" como um dos objetivos fundamentais da República Federativa do Brasil. A ideia de redução das desigualdades sociais é repetida no art. 170, VII que dispõe que a ordem econômica é fundada em valores como a justiça social e possui como princípio a redução das desigualdades sociais.

Os dois dispositivos trazem a redução das desigualdades sociais como diretriz a ser seguida pelo Estado guardando relação com o ideário de justiça fiscal, uma vez que a tributação pode ser utilizada como instrumento de redução das desigualdades sociais. Neste seguimento, Correia (2010) afirma que a utilização do tributo com o fim de reduzir as desigualdades sociais é oriundo da própria função social que é inerente ao tributo e acrescenta que deve ser um fim perseguido já que deve prevalecer o interesse social e a construção do comum.

O tributo tem a função social de contribuir para com a ponderação das desigualdades sociais, de forma que os contribuintes recebam o retorno do Estado, em termos de serviços. Na verdade, os contribuintes cooperam com o sacrifício de parte de seu patrimônio, na medida de sua capacidade contributiva, para que o interesse coletivo seja prestigiado, buscando-se a instauração de um clima de paz, segurança e prosperidade, do qual todos são beneficiados, mesmo aqueles que nada contribuíram, por serem "isentos", "imunes" ou não deterem capacidade para tanto. 
Desta forma, o tributo tem o condão de fazer prevalecer o interesse social sobre o interesse particular. (CORREIA, 2010, p.113)

Sustenta, ainda, a doutrinadora que não só o tributo tem o condão de reduzir as disparidades de distribuição como o Estado tem o dever de intervir no mercado econômico para promover esta maior equidade na distribuição da renda, mas isso só é possível se a tributação for aplicada de forma racional. Assim, "por meio da racional tributação é que podem ser diminuídas as distâncias que separam a minoria de pessoas que detém grande concentração de riqueza individual, e a maioria dos que não têm praticamente nenhuma riqueza particular" (CORREIA, 2010, p.113).

Na mesma linha de raciocínio, Silva (2010) afirma que somente com a aplicação do princípio da capacidade contributiva é possível a utilização da tributação com o intuito de promover a redução das desigualdades sociais, declarando que "se aplicado como parâmetro para majoração e instituição dos tributos, sempre que isto se fizer possível, é um grande instrumento contra a desigualdade social que, uma carga tributária mal dividida pode vir a gerar" (SILVA, 2010, p.116).

Baptista mesmo apontando críticas à eficácia e à avaliação da capacidade contributiva não refuta a ideia de que o princípio da capacidade contributiva é instrumento indispensável para a concretização da justiça fiscal, ao contrário, vai além, afirmando que além de justiça fiscal é possível alcançar a justiça social através do princípio da capacidade contributiva. Segundo Baptista (2007, p. 130) "tributando cada um na medida de suas possibilidades o princípio respeita a igualdade tão sonhada e perseguida. $\mathrm{O}$ valor arrecadado justamente retorna à sociedade sob a forma de investimentos para aqueles que são mais necessitados". Destacando os investimentos na educação, cultura e informação.

Ressalte-se, que tais investimentos são capazes de melhorar a vida das pessoas possibilitando igualdade de condições. Para tanto, além da arrecadação adequada respeitando a capacidade contributiva é necessário à alocação correta dos recursos arrecadados, promovendo a inclusão social. Neste sentido:

Com uma arrecadação na medida ideal e uma política sincera, esse valor poderia voltar a sociedade sob a forma de investimento na educação, cultura e informação das pessoas e melhora da vida delas redistribuindo e alocando devidamente os bens disponíveis na sociedade. 
A alocação correta dos bens de produção e de consumo daria aos indivíduos componentes de nossa sociedade subsídios necessários para que haja uma igualdade de condições materiais (bens de produção de consumo) e imateriais (acesso a cultura, educação e lazer). (BAPTISTA, 2007, p. 131)

Acerca da distribuição dos bens na sociedade, Iatarola (2005) anuncia que esta distribuição dos bens na sociedade é denominada de princípio da diferença, tendo três pressupostos. O primeiro pressuposto é a distribuição no âmbito dos bens de forma a trazer um benefício maior para os mais desfavorecidos. O segundo pressuposto é a possibilidade de todos os indivíduos ocuparem posições e funções na sociedade. E por fim, o terceiro pressuposto é que os indivíduos tenham igualdade de oportunidades com condições mínimas de existência.

Como visto anteriormente no caso dos tributos indiretos sobre o alimento, em razão da garantia da proteção existencial, o princípio da capacidade contributiva será realizado através de desoneração total desta tributação. Com isto além de proteger o mínimo existencial estará se promovendo a redução das desigualdades sociais, conforme a lição de Araújo:

Os efeitos de políticas tributárias, tanto desonerações de alimentos quanto de
insumos, são discutidos por autores como (Santos e Ferreira Filho 2007) que analisa,
através de simulações baseadas em um modelo de equilíbrio geral inter-regional
calibrado para o ano de 2001 , o efeito de dois tipos de políticas tributárias relativas a
impostos indiretos: a redução dos tributos sobre alimentos; e a desoneração dos
principais insumos utilizados na agropecuária. As simulações apresentam resultados
semelhantes, sendo a política de redução da alíquota sobre alimentos aquela com
implicações mais intensas. O resultado obtido é uma expansão da atividade
econômica nas regiões mais pobres (Norte e Nordeste) e uma retração nas mais
ricas, enquanto que em termos de bem-estar da população todas as regiões são
beneficiadas (as mais pobres mais intensamente). (ARAUJO, 2005, p. 20)

Assim, o princípio da capacidade contributiva, conforme já exposto anteriormente, é instrumento concretizador da igualdade material, almejando a realização da justiça social, ou seja, é instrumento apto a promover a redução das desigualdades sociais.

Ocorre que nos casos de tributação sobre consumo, ou seja, tributação indireta, que é inviável a analise da capacidade econômica do contribuinte, surgindo o questionamento de como a capacidade contributiva será utilizada para a proteção do mínimo existencial e da dignidade humana.

\author{
Revista de Direito Sociais e Políticas Públicas | e-ISSN: 2525-9881 | Belém | v. 5 | n. 2 | \\ p. 103 - 120 | Jul/Dez. 2019.
}


Nos tributos indiretos a capacidade contributiva será concretizada através da seletividade, pela qual incidirá uma carga tributária menor para produtos essenciais e uma maior carga tributária para os produtos mais supérfluos.

Entretanto, em alguns casos, mesmo com aplicação da seletividade não garantirá a proteção do mínimo existencial e da dignidade humana, em outras palavras, nos tributos indiretos mesmo se aplicando a seletividade pode ocorrer situações em que a tributação mesmo sendo muito branda poderá prejudicar o mínimo existencial e a dignidade de determinado cidadão.

A solução apontada por CARRAZZA (2013) para a problemática da aplicação do princípio da capacidade contributiva aos tributos indiretos é pela não incidência sobre os bens e produtos essenciais à garantia do mínimo existencial, apontando como exemplo o bens que compõem a cesta básica.

No mesmo sentido, destacamos os ensinamentos de Regina Helena Costa

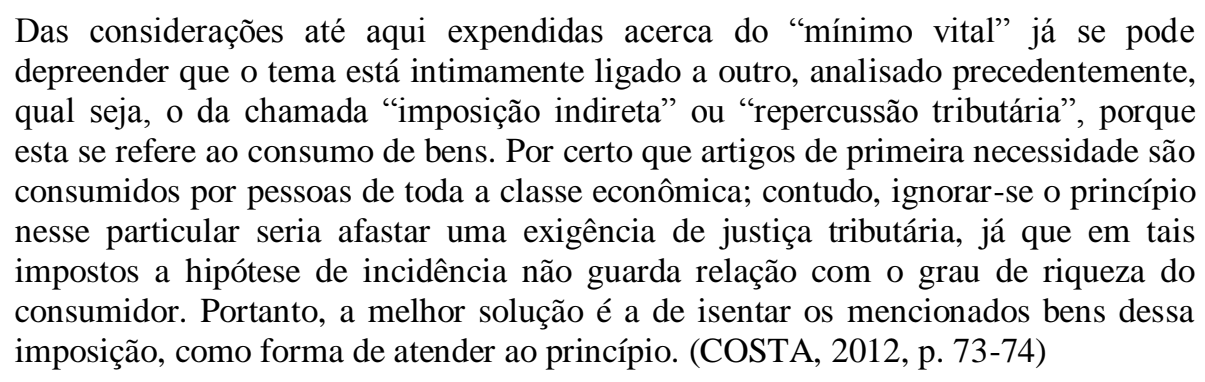

Portanto, como solução para a problemática da identificação da capacidade contributiva, o que pode acarretar consequências nefastas para o mínimo existencial e para a dignidade humanada, defende-se a isenção dos produtos de primeira necessidade.

\section{CONSIDERAÇÕES FINAIS}

O Estado tem o dever constitucional de implementar uma política fiscal norteada pela justiça fiscal de modo a balancear os deveres e direitos dos indivíduos, ou seja, de modo que o dever de recolher os tributos seja distribuído de forma equânime entre os indivíduos respeitando a capacidade contributiva de cada cidadão.

O princípio da capacidade contributiva, previsto na Constituição Federal, é o instrumento adequado para a distribuição do encargo tributário de forma que cada individuo 
contribua nos limites de sua capacidade econômica, de forma a não ser compelido a pagar mais ou menos do que pode.

Ao tributar menos quem pode pagar menos e tributar mais quem pode pagar mais o Estado evita a ampliação das desigualdades sociais e concomitantemente permite a arrecadação de recursos que permitem a continuidade dos serviços públicos, a concretização de direitos fundamentais e a implementação de ações positivas para redução das desigualdades sociais. Assim, ao realizar ações com a finalidade de aplicar o princípio da capacidade contributiva o Estado esta implementando políticas publicas para reduzir as desigualdades sociais.

Deste modo, a aplicação do princípio constitucional da capacidade contributiva num primeiro momento concretizaria da justiça fiscal, implicando numa igualdade econômica, porém, posteriormente, concretizaria a justiça social, promovendo redução das desigualdades sociais e igualdade de oportunidades.

O sistema tributário prevê ferramentas para a graduação do tributo segundo a capacidade econômica do contribuinte, tais como a progressividade, a proporcionalidade, a seletividade e as isenções/imunidades.

A priori o Estado deve buscar aplicar a progressividade que é a forma mais adequada para a distribuição do ônus tributário, somente nos caso em que não for possível deverá a tributação ser proporcional.

Nos casos da tributação sobre o consumo, tributação indireta, que não é possível uma analise e verificação da capacidade contributiva o Estado deve instituir uma tributação seletiva, com uma carga tributária mais elevada para produtos mais supérfluos e mais branda para produtos mais essenciais, e implementar isenções ou imunidades para produtos que integram o mínimo existencial, considerando que a parcela da renda destinada à garantida do mínimo existencial e da dignidade humana devem ser excluídas da analise da capacidade contributiva, não devendo ser tributada.

\section{REFERÊNCIAS}

ARAUJO, Ewerton Felipe de Melo. Impacto da desoneração da cesta básica e do aumento do Programa Bolsa Família sobre a utilidade da classe baixa e nível de focalização do 
PBF que iguala os efeitos das duas políticas. $50 \mathrm{f}$. Dissertação (Mestrado em Economia) Universidade Federal de Pernambuco, CCSA, Recife, 2015.

AZEVEDO, Naiara Silveira. O Princípio da Capacidade Contributiva e seus mecanismos para efetividade da Justiça Fiscal. 102 f. Dissertação (Programa de Mestrado em Direito) Centro Universitário FIEO, Osasco, 2013.

AZEVEDO, Plauto Faraco de. Justiça distributiva e aplicação do direito. Porto Alegre: Fabris, 1998.

BAPTISTA, Hélio Daniel de Favare. Justiça tributária, justiça distributiva e solidariedade social: aplicação do princípio da capacidade contributiva. $139 \mathrm{f}$. Dissertação (Programa de Mestrado em Direito) - Centro Universitário de Marília, Marília, 2007.

CARRAZZA, Roque Antonio. Curso de direito constitucional tributário. 30. ed. São Paulo: Malheiros, 2015.

CONTI, José Maurício. Princípios tributários da capacidade contributiva e da progressividade. São Paulo: Dialética, 1997.

CORREIA, Emanuelle Araújo. A efetividade dos incentivos fiscais ambientais por meio de políticas públicas para a redução das desigualdades regionais. $135 \mathrm{f}$. Dissertação (Mestrado em direito) - Universidade de Marília, Marilia, 2010.

COSTA, Regina Helena. Princípio da capacidade contributiva. 4. ed. São Paulo: Malheiros, 2012.

GIOTTI, Daniel. Solidariedade, moralidade e eficiência como critérios de justiça tributária. In: FUX, L.; QUEIROZ, L. C. S. de; ABRAHAM, M. (Org.). Tributação e justiça fiscal. Rio de Janeiro: GZ, 2014. p. 131-158.

IATAROLA, Ana Cristina Silva. CAPACIDADE CONTRIBUTIVA Princípio norteador de justiça tributária e sua limitação pelos direitos fundamentais: mínimo existencial versus não confisco tributário. $151 \mathrm{f}$. Dissertação (Mestrado em Direito) - Universidade Gama Filho, Rio de Janeiro, 2005.

MELLO, Elizabete Rosa de. Direito fundamental a uma tributação justa. São Paulo: Atlas, 2013.

MENESCAL, Ana Mônica Filgueiras. A seletividade como instrumento concretizador da justiça fiscal no âmbito do ICMS. 188 f. Dissertação (Programa de Pós-Graduação em Direito Constitucional - Mestrado e Doutorado) - Universidade de Fortaleza, Fortaleza, 2007.

MORSCH, Natália de Azevedo. Justiça fiscal e neutralidade fiscal: a questão do ICMS nas operações interestaduais. 181 f. Dissertação (Programa de Pós-Graduação em Direito Mestrado) - Pontifícia Universidade Católica do Rio Grande do Sul, Porto Alegre, 2006. 
NOBRE JÚNIOR, Edilson Pereira. Princípio constitucional da capacidade contributiva. Porto Alegre: Sergio Antonio Fabris Editor, 2001.

PERES, Eliane Lamarca Simões. Justiça fiscal e progressividade. 1. ed. Rio de Janeiro: Lumen Juris, 2013.

PEZZI, Alexandra Cristina Giacomet. Dignidade da pessoa humana: mínimo existencial e limitação à tributação no estado democrático de direito. 1. ed. Curitiba: Juruá, 2011.

PNUD/RDH. Relatório de desenvolvimento humano 2017 - desenvolvimento humano para todas as pessoas. N. York, PNUD/ONU, 2017. Disponível em:

http://www.br.undp.org/content/brazil/pt/home/presscenter/articles/2018/brasil-mantemtendencia-de-avanco-no-desenvolvimento-humano--mas.html. Acesso em: 2 de jan. 2019.

PORTO, Éderson Garin. A colaboração no direito tributário: por um novo perfil de relação obrigacional tributária. Porto Alegre: Livraria do Advogado Editora, 2016.

SILVA, Bárbara Raquel de Azevedo da. O princípio da capacidade contributiva e sua relação com a (des)igualdade social. 121 f. Dissertação (Programa de Pós-Graduação em Direito - Mestrado) - Universidade do Vale do Rio dos Sinos - UNISINOS, São Leopoldo, 2010 .

TIPKE, Klaus; YAMASHITA, Douglas. Justiça fiscal e princípio da capacidade contributiva. São Paulo: Malheiros, 2002.

TORRES, Ricardo Lobo. Justiça distributiva: social, política e fiscal, in Revista de Direito Tributário no 70. São Paulo: Malheiros, S.d., p. 27-39.

ZILVETI, Fernando Aurelio. Princípios de direito tributário e a capacidade contributiva. São Paulo: Quartier Latin, 2004. 